\title{
Furfural Hydrodeoxygenation over a Ruthenium-Based Bifunctional Catalyst in the Presence of a Direct Source of $\mathbf{H}_{2}$
}

\author{
Adriano F. de Sousa,$^{a, b}$ Elisane Longhinotti, ${ }^{\circ b}$ Antoninho Valentini ${ }^{b}$ and \\ Izaura C. N. Diógenes ${ }^{(\circledR)} *$ \\ ${ }^{a}$ Departamento de Química, Instituto Federal de Educação, Ciência e Tecnologia, \\ 62680-000 Paracuru-CE, Brazil \\ ${ }^{b}$ Departamento de Química Analítica e Físico-Química, Universidade Federal do Ceará, \\ Campus do Pici, 60455-970 Fortaleza-CE, Brazil \\ 'Departamento de Química Orgânica e Inorgânica, Universidade Federal do Ceará, \\ Campus do Pici, 60455-970 Fortaleza-CE, Brazil
}

\begin{abstract}
This work presents the results obtained for the gas chromatography-mass spectrometry (GC-MS) monitoring of the liquid-phase hydrodeoxygenation (HDO) reaction of furfural (FFR) to 2-methylfuran (MF) over a bifunctional $\mathrm{Ru} / \mathrm{RuO}_{x} / \mathrm{C}$ catalyst in the presence of a direct source of $\mathrm{H}_{2}$. Hydrogenation and hydrogenolysis reactions of FFR and of the intermediate furfuryl alcohol (FA), respectively, were independently studied to provide insights on the HDO mechanism. The mass spectra monitoring of the kinetic isotope effect indicated the HDO reaction occurs through a twostep mechanism comprising of an initial ruthenium-mediated hydrogenation reaction of FFR to FA. In the second step, the FA thus formed experiences a hydrogenolysis reaction via ring activation where the hydrogen atoms are firstly attached to the $\mathrm{C} 3$ carbon generating a ring activated structure and removing the $\mathrm{OH}$ group. The observation of the peaks at $\mathrm{m} / \mathrm{z} 85$ and 84 in the mass spectrum of the MF product confirms this reaction pathway.
\end{abstract}

Keywords: heterogeneous catalysis, hydrodeoxygenation, furfural, 2-methylfuran, kinetic isotope effect

\section{Introduction}

Focusing on the development of alternative fuels to avoid the use of the fossil ones, biofuels have been long considered an option that follows highly relevant issues such as sustainability and environmental friendly. ${ }^{1}$ As part of ongoing researches, biomass fuels emerge as a promising alternative due to the widely availability worldwide. In this context, lignocellulosic biomass provides a renewable route to carbon-based fuels and chemicals in the production of the so called second generation biofuels, especially regarding low income countries in the sense that such source is not related to food production. ${ }^{1}$ The synthesis of biofuels from lignocellulosic biomass is mainly dependent on the fermentation step of the sugars restrained in the polymer matrix, thus making necessary the breakdown of the lignin structure to their removal. Several pretreatment methods have been proposed to overcome the most

*e-mail: izaura@dqoi.ufc.br costly step in converting lignocellulosic biomass into biofuel: the removal of lignin to open the lignocellulosic structure. ${ }^{1-10}$ The majority of the pretreatments (physical and chemical), however, results in considerable amounts of unwanted inhibitors such as 5-hydroxymethylfurfural (HMF) and furfural (FFR) that retard or even stop the sugar fermentation. On the other hand, the by-products HMF and FFR are currently seen as chemical platforms because of the potential application in producing valueadded compounds. In fact, while the processing of lignin remains elusive, cellulose and hemicellulose components of lignocellulosic biomass are well-studied in their selective transformations to such chemical platforms. ${ }^{11-15}$ FFR, for instance, has been catalytically reduced to produce 2-methylfuran, cyclopentanone, 2-methyltetrahydrofuran, and furfuryl alcohol (FA). ${ }^{11,14,16-18}$ Owing to the low energy density and high reactivity due to the presence of oxygen-rich side groups, hydrodeoxygenation (HDO) processes are imperative steps in the reductive conversion of FFR. Typically, the processes to selectively form the 
high-valued 2-methylfuran (MF) product from FFR follow gas- or liquid-phase hydrogenations over supported metallic catalysts with hydrogen donor. ${ }^{16,18-24}$ Despite the essential need of a deeper knowledge on the interaction between substrates and catalysts to further improve the development and optimization of catalysts, only about $13 \%$ of the published works focus on the mechanism revealing the concern of the researchers on the data production itself rather than on the chemical aspects of the process (literature search for the keywords "catalysis", "substrate" and "mechanism" at Web of ScienceTM Core Collection). ${ }^{25}$ For the catalytic liquid-phase conversion of FFR to MF by a bifunctional $\mathrm{Ru} / \mathrm{RuO}_{\mathrm{x}} / \mathrm{C}$ catalyst, a relevant work published by Gilkey et al..$^{14}$ using isopropyl alcohol as an indirect hydrogen source, showed that the HDO reaction of FFR takes place through a two-step mechanism. In the first step, there is a Lewis acid-mediated intermolecular hydride transfer to generate furfuryl alcohol (FA) that is catalyzed by $\mathrm{RuO}_{\mathrm{x}}$ sites. In the second step, which is the hydrogenolysis of FA to MF, the mechanism involves a ring activation that is facilitated by both the metal $(\mathrm{Ru})$ and Lewis acid $\left(\mathrm{RuO}_{x}\right)$ sites. The role of the hydrogen in the latter step, however, is still under debate. In addition, the authors proved the catalytic efficiency is strongly sensitive to the bifunctional nature of the catalyst.

In this work, we present the results for the liquid-phase conversion of FFR to MF using a commercial Ru/C catalyst mildly oxidized $\left(\mathrm{Ru} / \mathrm{RuO}_{\mathrm{x}} / \mathrm{C}\right)$ in presence of a direct source of $\mathrm{H}_{2}$. The HDO and hydrogenolysis reactions were independently studied using FFR and FA as starting reactants, respectively. Aiming to get insights on the influence of the hydrogen sources in the mechanism of the HDO reaction of FFR, the experiments were performed taking into account the temperature and kinetic isotopic effects.

\section{Experimental}

Commercial Ru/C catalyst (5\% Ru supported on carbon, Sigma-Aldrich, St Louis, USA) was mildly oxidized to $\mathrm{Ru} / \mathrm{RuO}_{\mathrm{x}} / \mathrm{C}$ following the procedure described by Panagiotopoulou et al. ${ }^{16}$ The catalyst was first loaded in a quartz tube and reduced in a furnace under $\mathrm{H}_{2} / \mathrm{He}$ flow $\left(20 \mathrm{~mL} \mathrm{~min}{ }^{-1} \mathrm{H}_{2}, 20 \mathrm{~mL} \mathrm{~min}{ }^{-1} \mathrm{He}\right.$ ) at $300{ }^{\circ} \mathrm{C}$ for $3 \mathrm{~h}$ and then oxidized at $130{ }^{\circ} \mathrm{C}$ for $3 \mathrm{~h}$ under $5 \% \mathrm{O}_{2}$ in $\mathrm{He}$ flow $\left(40 \mathrm{~mL} \mathrm{~min}^{-1}\right)$. The profile of the temperature-programmed reduction (TPR) curve of the reduced/oxidized catalyst is in accordance with that reported for the bifunctional $\mathrm{Ru} / \mathrm{RuO}_{\mathrm{x}} / \mathrm{C}$ catalyst as prepared by Jae et al. ${ }^{26}$

$\mathrm{HDO}$ and hydrogenolysis reactions were carried out in a $100 \mathrm{~mL}$ stainless steel Parr reactor with magnetic stirring containing $100 \mathrm{mg}$ of pretreated $\mathrm{Ru} / \mathrm{C}$ catalyst dispersed in a $24.18 \mathrm{~mL}$ mixture of $0.18 \mathrm{~mL}$ furfural (99\%, SigmaAldrich, St Louis, USA) or $0.18 \mathrm{~mL}$ furfuryl alcohol (98\%, Sigma-Aldrich, St Louis, USA), respectively, in $24.0 \mathrm{~mL}$ toluene (99.5\%, Sigma-Aldrich, St Louis, USA). The reactor containing $101.325 \mathrm{kPa}$ of $\mathrm{H}_{2}$ or $\mathrm{D}_{2}$ (99.8\%, Cambridge Isotope Laboratory, Tewksbury, USA) was pressurized to $2.068 \mathrm{MPa}$ with $\mathrm{N}_{2}$ and placed in a pre-heated oil bath for different reaction times and temperatures followed by quenching in an ice bath. The final mixture was filtered by using a $0.2 \mu \mathrm{m}$ membrane nylon filter (Thermo Scientific) and stored in vials. Similar protocol was followed for the reactions performed with furfuryl alcohol (99\%, Sigma-Aldrich, St Louis, USA).

Post-reaction mixtures were analyzed by gas chromatography using a gas chromatograph coupled to mass spectrometer (GC-MS, Shimadzu QP2010 Plus) and gas chromatograph coupled to flame ionization detector (GC-FID, Agilent 7890A), both equipped with an HP-INNOWax capillary column ( $30 \mathrm{~m} \times 0.25 \mathrm{~mm} \times 0.50 \mu \mathrm{m}$ film thickness). Helium was used as carrier gas at a flow rate of $66.1 \mathrm{~mL} \mathrm{~min}^{-1}$, the injector temperature was $250^{\circ} \mathrm{C}$ and the detector was kept at $200{ }^{\circ} \mathrm{C}$. Moreover, split injection mode was used with split ratio of 1:20; the over temperature was programmed from $90{ }^{\circ} \mathrm{C}$ (isothermal for $5 \mathrm{~min}$ ), with an increase of $10{ }^{\circ} \mathrm{C} \mathrm{min}-1$ to $180{ }^{\circ} \mathrm{C}$ and an increase of $20^{\circ} \mathrm{C} \mathrm{min}^{-1}$ to $270{ }^{\circ} \mathrm{C}$ (isothermal for $8.7 \mathrm{~min}$ ). The mass spectrometer was operated under an ionization voltage of $70 \mathrm{eV}$ and an ion source temperature of $200{ }^{\circ} \mathrm{C}$, using SIM mode with mass range from 15 to $200 \mathrm{~m} / \mathrm{z}$. The response factors of the chromatograms were determined by using standard solutions of known concentrations. The chromatograms obtained for the HDO and hydrogenolysis reactions are shown as Figures S1 and S2, respectively, in the Supplementary Information (SI) section. Tables S1 and $\mathrm{S} 2$ were also added to display the data (retention time and peak areas) of the chromatograms. Identification of the GC-MS spectral features was accomplished by comparing the mass fragmentation pattern of the products with those in the built-in Wiley/NIST library.

Assuming conversion (C) is the transformation of the starting material FFR or FA and yield $\left(\mathrm{Y}_{\mathrm{i}}\right)$ is the amount of the reaction product, these parameters were calculated according to equations 1 to 4 :

$$
\begin{aligned}
& \mathrm{C}=\left[1-\frac{\left(\mathrm{n}_{\mathrm{FFR}}\right)_{\mathrm{f}}}{\left(\mathrm{n}_{\mathrm{FFR}}\right)_{\mathrm{i}}}\right] \\
& \mathrm{C}=\left[1-\frac{\left(\mathrm{n}_{\mathrm{FA}}\right)_{\mathrm{f}}}{\left(\mathrm{n}_{\mathrm{FA}}\right)_{\mathrm{i}}}\right]
\end{aligned}
$$




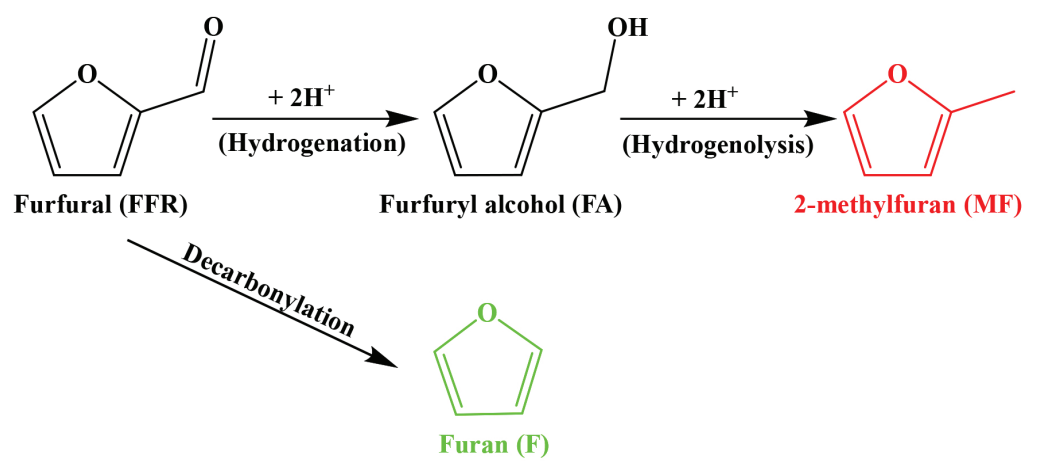

Scheme 1. Illustration of the HDO reaction of FFR to MF including the formation of the furan by-product.

$Y_{i}=\left[\frac{\left(n_{i}\right)_{f}}{\left(n_{F F R}\right)_{i}}\right]$

$Y_{i}=\left[\frac{\left(n_{i}\right)_{f}}{\left(n_{F A}\right)_{i}}\right]$

where $\mathrm{n}_{\mathrm{FFR}}$ and $\mathrm{n}_{\mathrm{FA}}$ are the number of moles of furfural and furfuryl alcohol, respectively, and $n_{i}$ is the number of moles of the reaction product.

For the calculation of $\mathrm{C}$ and $\mathrm{Y}_{\mathrm{i}}$, the starting values $(0 \mathrm{~h}$ of reaction) were considered at the very time the system reached a specific temperature.

\section{Results and Discussion}

As previously commented, the conversion of FFR to MF occurs through a two-step mechanism involving the formation of FA as intermediate,,$^{14}$ as shown in Scheme 1 where furan $(\mathrm{F})$, the by-product, is also represented.

Temperature, kinetics, and hydrogen sources were evaluated as reaction parameters for the hydrodeoxygenation (HDO) and hydrogenolysis reactions of FFR and FA, respectively.

\section{Effect of temperature}

The conversion and the product yields of the HDO reaction of FFR over $\mathrm{Ru} / \mathrm{RuO}_{x} / \mathrm{C}$ catalyst, as quantified by $\mathrm{GC}$, shown to be dependent on the temperature, as can be ascertained from Figure 1.

Accounting that the HDO conversion of FFR to MF is favored at high temperatures, ${ }^{27,28}$ below $110{ }^{\circ} \mathrm{C}$ only about $8 \%$ of conversion is observed with furan as the major identified product $\left(\mathrm{Y}_{\mathrm{F}}\right.$ ca. 3\%). As the temperature is increased, $\mathrm{MF}$ ( $\mathrm{Y}_{\mathrm{MF}}$, Figure 1, red curve) is selectively produced while no FA is detected. The absence of FA can be explained based on three hypotheses as follows: (i) FA is formed and is immediately converted to other

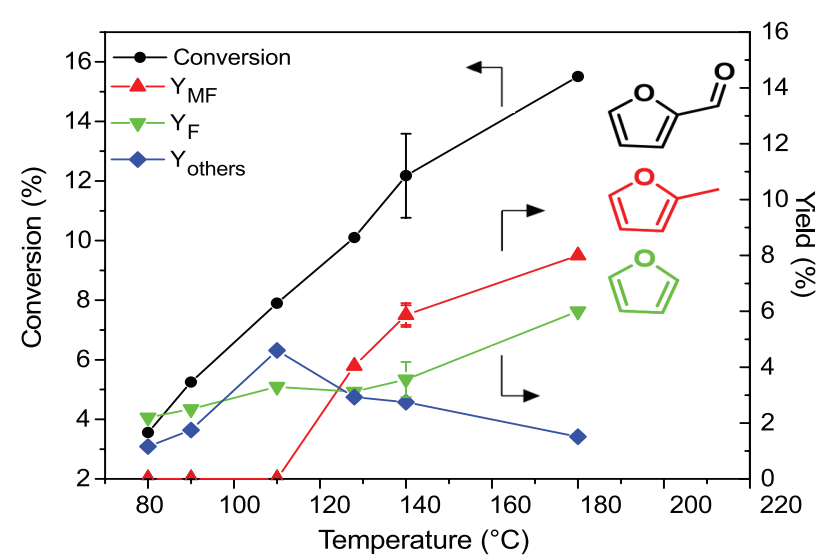

Figure 1. Temperature dependence for the HDO reaction of FFR over $\mathrm{Ru} / \mathrm{RuO}_{\mathrm{x}} / \mathrm{C}$ catalyst. Conditions: reaction time of $2 \mathrm{~h}$ in toluene containing 1 wt.\% FFR, $100 \mathrm{mg} \mathrm{Ru} / \mathrm{RuO}_{\mathrm{x}} / \mathrm{C}$, and $\mathrm{P}=2.068 \mathrm{MPa}\left(\mathrm{H}_{2} / \mathrm{N}_{2}\right)$.

products; (ii) FA-like intermediate is formed, e.g., furfuryl alkoxy $\left(\mathrm{C}_{5} \mathrm{H}_{3} \mathrm{O}-\mathrm{CH}_{2} \mathrm{O}_{\mathrm{ad}}\right)$; and (iii) $\mathrm{HDO}$ reaction does not proceed through the FA intermediate. Knowing $\mathrm{Ru} / \mathrm{C}$ catalysts induce the conversion of FFR to FA prior to the hydrogenolysis step both in the presence of direct and indirect hydrogen sources, ${ }^{16,28-30}$ the third hypothesis is the least likely.

The low carbon balance at low temperatures (ca. 37\% from 80 to $110^{\circ} \mathrm{C}$ ) is assigned to the formation of by-products, such as high molecular weight oligomers. ${ }^{31,32}$ Considering that these species are probably formed by the hydrogenolysis of FA, the monitoring of this reaction was performed by GC and the product yields are shown in Figure 2. Indeed, the conversion of FA into these high molecular weight oligomers results in ca. $18 \%$ at $110^{\circ} \mathrm{C}$. It is worth mentioning that this yield is related to a mixture of oligomers and not to a specific compound. Similar observation was reported by Jae et al. ${ }^{33}$ for the same catalyst. As observed for the conversion of FFR to MF (Figure 1), the MF production from FA increases with the temperature increase.

The conversion of FA was observed to be more than three times higher than FFR, under the same 

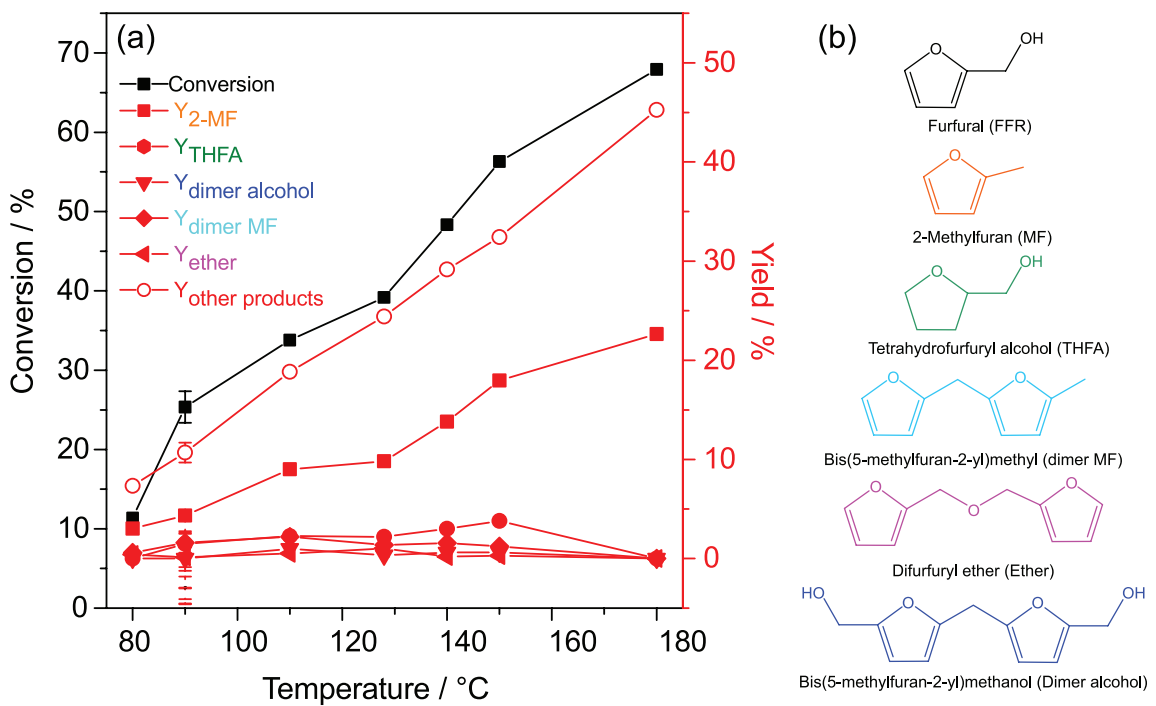

Figure 2. (a) Temperature dependence for the hydrogenolysis reaction of $\mathrm{FA}$ over $\mathrm{Ru} / \mathrm{RuO}_{\mathrm{x}} / \mathrm{C}$ catalyst. Conditions: reaction time of $2 \mathrm{~h}$ in toluene containing 1 wt. $\% \mathrm{FA}, 100 \mathrm{mg} \mathrm{Ru} / \mathrm{RuO}_{\mathrm{x}} / \mathrm{C}$, and $\mathrm{P}=2.068 \mathrm{MPa}\left(\mathrm{H}_{2} / \mathrm{N}_{2}\right)$; (b) structures of the identified products.

experimental conditions, with $\mathrm{MF}$ as the major identified product $\left(\mathrm{Y}_{\mathrm{MF}}\right.$ ca. 20\%), Figure 2. Also, no furan was detected indicating that this product is formed from the decarbonylation of FFR. ${ }^{34}$ This result, besides discarding the second hypothesis, reinforces the first hypothesis in which the formation of the FA intermediate is a necessary step to obtain the MF product corroborating the mechanism proposed in the literature for the HDO reaction with direct hydrogen source. ${ }^{35}$ In addition, it was detected small amounts of tetrahydrofurfuryl alcohol (THFA) and ether $\left(\mathrm{Y}_{\text {ether }}<3 \%\right)$ resulting from the ring hydrogenation.

Kinetic studies

Figure 3 shows the kinetic data for the conversion and product yields for the HDO and hydrogenolysis reactions

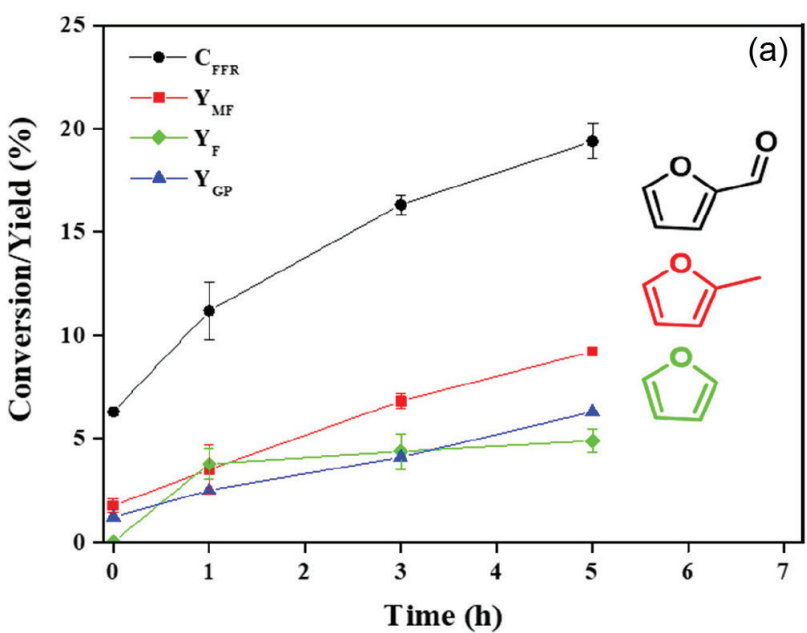

of FFR and FA, respectively. These studies were performed at different temperatures because of the higher reactivity of FA as can be seen when comparing the data shown in Figures 1 and 2.

The conversion of FFR was monitored at $140{ }^{\circ} \mathrm{C}$ for $5 \mathrm{~h}$ and the results show the production increase of MF and furan (Figure 3a). After $5 \mathrm{~h}$ of reaction, MF yield reaches ca. $8 \%$ while no FA is observed even at short times corroborating with the first hypothesis where the putative formed FA is instantaneously converted to MF. A significant portion of the FFR conversion is attributed to the cracking of $\mathrm{C}-\mathrm{C}$ bonds toward gaseous hydrocarbons, as indicated by the yield of gas-phase $\left(\mathrm{Y}_{\mathrm{GP}}\right)$ products in Figure 3a. The incorporation of the gas-phase products into the analysis results in nearly $100 \%$ of carbon balance after $5 \mathrm{~h}$ of reaction. Further, the reactor headspace analysis indicates

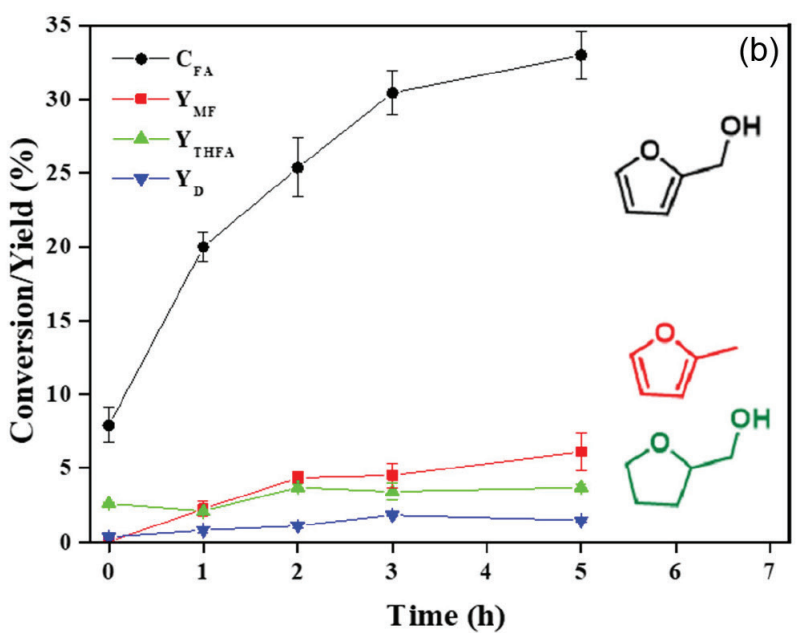

Figure 3. Kinetic curves for (a) FFR at $140{ }^{\circ} \mathrm{C}$, and (b) FA at $90{ }^{\circ} \mathrm{C}$. Conditions: $100 \mathrm{mg} \mathrm{Ru} / \mathrm{RuO}_{\vee} / \mathrm{C}, \mathrm{P}=2.068 \mathrm{MPa}\left(\mathrm{H}_{2} / \mathrm{N}_{2}\right)$, and toluene containing 1 wt.\% of (a) FFR and (b) FA. $C_{\mathrm{FFR}}$ and $\mathrm{C}_{\mathrm{FA}}$ refer to the conversion of FFR and FA, respectively. $\mathrm{Y}_{\mathrm{MF}}, \mathrm{Y}_{\mathrm{F}}, \mathrm{Y}_{\mathrm{THFA}}, \mathrm{Y}_{\mathrm{GP}}$ and $\mathrm{Y}_{\mathrm{D}}$ stand for the yield curves of MF, furan, THFA, gas-phase, and dimers (see Experimental section for calculation details). 
that the gas-phase products are composed of hydrocarbons, as summarized in Table 1. This result contrasts with the work previously conducted over $\mathrm{Ru} / \mathrm{C}$ in 2-propanol as solvent, ${ }^{14}$ where nearly $100 \%$ carbon balance was attained without the existence of gas-phase products suggesting the $\mathrm{H}_{2}$ source plays an essential role in tuning the FFR HDO chemistry.

Table 1. Percentage of yields of gas-phase products formed from the HDO reaction of FFR. Conditions: $100 \mathrm{mg} \mathrm{Ru} / \mathrm{RuO}_{\mathrm{x}} / \mathrm{C}, \mathrm{P}=2.068 \mathrm{MPa}$ $\left(\mathrm{H}_{2} / \mathrm{N}_{2}\right)$, and toluene containing $1 \mathrm{wt} . \%$ FFR

\begin{tabular}{|c|c|c|c|c|c|}
\hline time / $\mathrm{h}$ & & 0 & 1 & 3 & 5 \\
\hline \multicolumn{2}{|c|}{ Compounds } & \multicolumn{4}{|c|}{ Yield / \% } \\
\hline $\mathrm{C}_{1}$ & methane & 0.29 & 0.39 & 0.60 & 0.54 \\
\hline \multirow{2}{*}{$\mathrm{C}_{2}$} & ethane & 0.03 & 0.41 & 0.55 & 0.60 \\
\hline & ethene & 0.14 & 0.12 & 0.58 & 0.70 \\
\hline \multirow{2}{*}{$\mathrm{C}_{3}$} & propane & nd & 0.49 & nd & 1.09 \\
\hline & propene & 0.15 & 0.20 & 0.70 & nd \\
\hline \multirow{3}{*}{$\mathrm{C}_{4}$} & butane & nd & nd & 0.01 & nd \\
\hline & isobutane & nd & 0.13 & 0.03 & 0.90 \\
\hline & butene & nd & 0.30 & 0.86 & 1.17 \\
\hline $\mathrm{C}_{5}$ & pentane & nd & 0.13 & 0.48 & 0.66 \\
\hline $\mathrm{C}_{6}$ & hexane & 0.08 & 0.21 & 0.25 & 0.72 \\
\hline \multicolumn{2}{|l|}{ Total } & 0.69 & 2.38 & 4.06 & 6.38 \\
\hline
\end{tabular}

nd: non-detected.

The conversion of FA after $5 \mathrm{~h}$ of reaction at $90{ }^{\circ} \mathrm{C}$ (Figure $3 \mathrm{~b}$ ) produces MF, THFA and dimers. In fact, as discussed in the studies of the temperature dependence for the hydrogenolysis reaction of FA (Figure 2), there is the production of a mixture of high molar mass compounds that were not identified and are, probably, responsible for the difference between the kinetic data of yield and conversion shown in Figure 3, where only the identified species were considered. As the conversion of FA is faster than FFR in the same experimental conditions, it is not surprising the comparative lower selectivity toward MF production (6.1 and $9.2 \%$ for FA and FFR, respectively). No gas-phase products were observed using FA as the starting material suggesting there is no cracking of the $\mathrm{C}-\mathrm{C}$ bonds. Taking into account that losses in carbon balance are generally attributed to the formation of non-identified products, being liquid- or gas-phase, the absence of gas-phase products in this work reinforces the hypothesis that FA is much more reactive in respect to the formation of liquid-phase products. The chromatographic analyses allowed the identification of two of these products, dimers (ca. 1.5\%) and THFA (ca. 3.7\%) but could not identify the other components even performing chromatography coupled to mass spectrometry.

\section{Kinetic isotopic effect}

Panagiotopoulou and Vlachos ${ }^{21}$ have shown that $\mathrm{Ru} / \mathrm{RuO}_{\mathrm{x}} / \mathrm{C}$ effectively catalyzes the HDO reaction of FFR to MF through a sequential two-step process involving, at first, a Lewis acid-mediated hydrogenation following the Meerwein-Ponndorf-Verley (MPV) mechanism and, second, a hydrogenolysis via ring activation having 2-propanol as hydrogen source. It is worth mentioning that the alcohol hydrogen transfer occurs via catalytic transfer hydrogenation $(\mathrm{CTH})$ mechanism..$^{14,21}$ In this work, as previously cited, no alcohol was used as hydrogen source, rather the HDO reaction was forward using a direct source of $\mathrm{H}_{2}$. Accordingly, the use of a direct $\mathrm{H}_{2}$ source eliminates both the CTH and MPV mechanisms indicating a metal-mediated hydrogenation must be the most likely pathway. For the hydrogenolysis step, two pathways can be considered, i.e., direct and ring activated hydrogenolyses. To shed light on the bond breaking steps, $\mathrm{D}_{2}$ was used to follow the intrinsic isotope effect on the hydrogenation and hydrogenolysis steps monitoring the reactions by GC-MS.

As shown in Figures $4 a$ and $4 b$, the kinetic data obtained demonstrate a significant kinetic isotope effect (KIE) in the conversions of FFR and FA.

Surprisingly, for the production of MF, the isotope effect is only operative when starting with FFR. This result indicates there is a rearrangement involving the $\mathrm{C} 1$ carbon atom, as schematically shown in Scheme 2.

For the hydrogenolysis reaction, Figure $4 \mathrm{~b}$, the fact there is no difference in the MF production when using $\mathrm{H}_{2}$ or $\mathrm{D}_{2}$ suggests another reaction pathway must be considered in which non-deuterated MF is produced (see Scheme 2). In fact, the results of the dependence of the yield on the temperature (Figure 3) showed a lower selectivity of FA towards the MF production in respect to FFR and that FA is likely generating liquid-phase species. It is reasonable to consider, hence, that deuterium is taking part in the formation of these species. In fact, the bar graph obtained from the mass spectra of MF produced in $\mathrm{H}_{2}$ and $\mathrm{D}_{2}$ from FA, Figure 4d, shows the most abundant fragment at $m / z 82$ for $\mathrm{H}_{2}$ and no fragmentation at $m / z, 84$ ascribed to species containing two deuterium atoms, thus corroborating the kinetic data. On the other hand, the bar graph obtained for MF from FFR, Figure 4c, reveals fragments at $\mathrm{m} / \mathrm{z}, 82$ for $\mathrm{H}_{2}$ and $m / z, 84$ and 85 for $\mathrm{D}_{2}$ indicating the attachment of two $\left(\mathrm{MS}+2, \mathrm{MF}-d_{2}\right)$ and three (MS + 3, MF- $d_{3}$ ) deuterium atoms, respectively. This result hints that the HDO reaction of FFR to MF follows, indeed, a sequential two-step mechanism, as shown in Scheme 3, with hydrogenation and hydrogenolysis reactions as the first and second steps, respectively. 
(a)

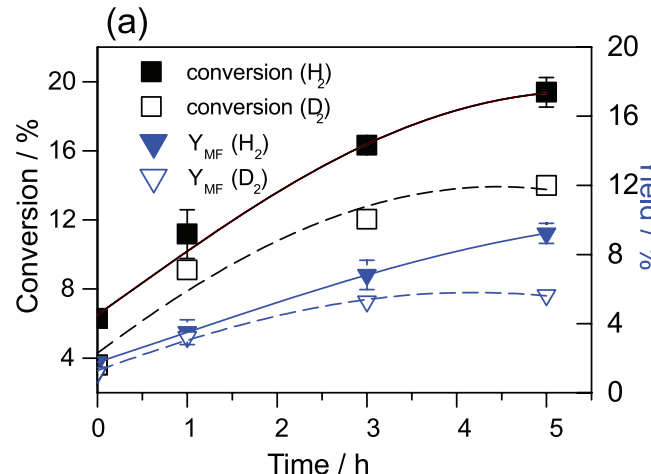

(c)

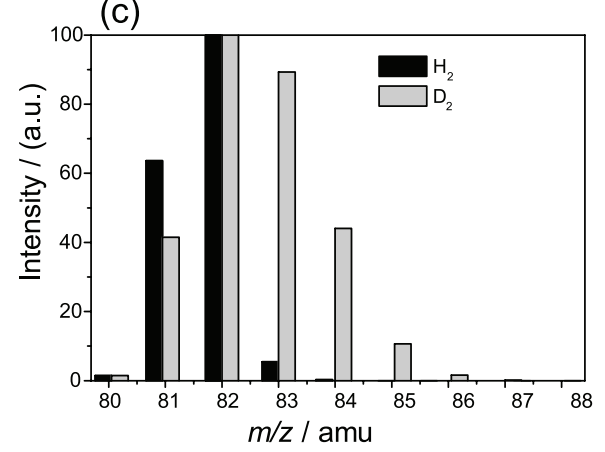

(b)

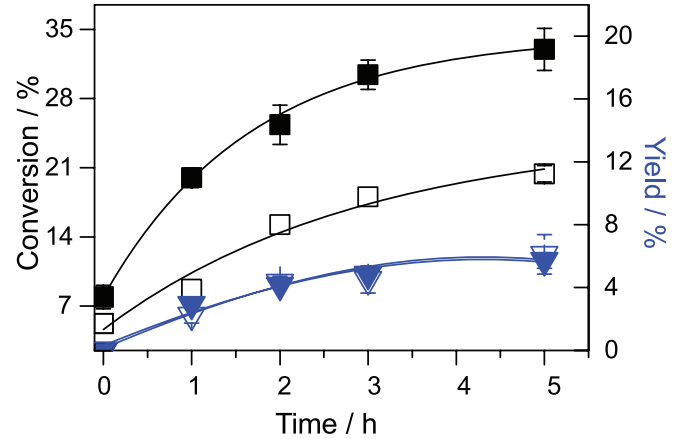

(d)

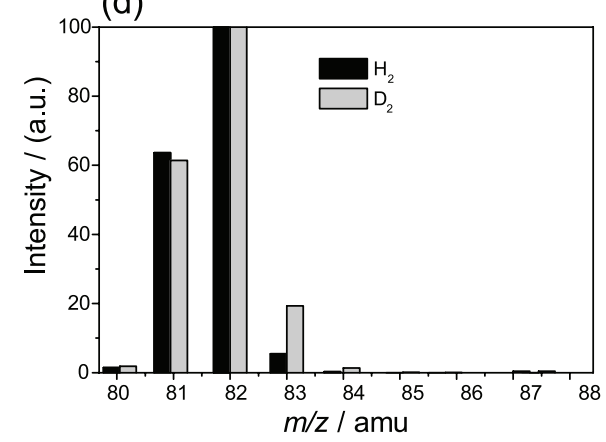

Figure 4. Kinetic curves obtained for MF yield and conversion of FFR at $140{ }^{\circ} \mathrm{C}$ (a) and FA at $90{ }^{\circ} \mathrm{C}$ (b) in $\mathrm{N}_{2}$ containing $\mathrm{H}_{2}$ (closed markers) and $\mathrm{D}_{2}$ (open markers). Conditions: $100 \mathrm{mg} \mathrm{Ru} / \mathrm{RuO}_{\mathrm{x}} / \mathrm{C}, \mathrm{P}=2.068 \mathrm{MPa}\left(\mathrm{N}_{2} / \mathrm{H}_{2}\right.$ or $\left.\mathrm{D}_{2}\right)$, and toluene containing 1 wt. $\%$ FFR or FA. Bar graphs of mass intensity as function of the $\mathrm{m} / \mathrm{z}$ ratio for MF after $3 \mathrm{~h}$ of reaction for FFR (c) and FA (d).<smiles>[CH][R1](C)c1ccc(C(P)P)o1</smiles><smiles>OC(c1ccco1)c1ccco1</smiles>

Scheme 2. Simplified representation of the isotopic labeling on MF produced from FFR and FA.

In the first step (left side of the Scheme 3) of the mechanism, it is proposed a ruthenium-mediated catalytic hydrogenation resulting in the production of FA. In the second step (right side of Scheme 3), the FA thus formed experiences a hydrogenolysis reaction via ring activation where the hydrogen atoms are firstly attached to the $\mathrm{C} 3$ carbon generating a ring activated structure and removing the $-\mathrm{OH}$ group. This pathway is confirmed by the observation of two signals in the mass spectra at $m / z, 85$ and 84 assigned, respectively, to MF- $d_{3}$ and MF- $d_{2}$ species. While the former species is formed upon the breaking of the $\mathrm{C} 3-\mathrm{H}$ bond followed by the hydrogenation of the $\mathrm{C} 1$ carbon, the MF- $d_{2}$ species is produced if the C3-D bond is broken.

\section{Conclusions}

This work presents data that show a successful study of the liquid-phase HDO reaction of FFR to MF over a bifunctional $\mathrm{Ru} / \mathrm{RuO}_{\mathrm{x}} / \mathrm{C}$ catalyst in the presence of a direct source of $\mathrm{H}_{2}$. The reaction was performed in different experimental conditions that were monitored by GC-MS whose data allowed not only the quantification of the conversion of FFR to MF, but also a kinetic study using deuterium for the isotopic labelling of the product aiming the proposition of a reasonable mechanism. To reach such goal, the second step of the HDO reaction, the hydrogenolysis of the intermediate FA, was independently studied to provide clues on the global process. The HDO reaction of FFR shown to be dependent on the temperature with no production of the FA intermediate below $110^{\circ} \mathrm{C}$ and a conversion enhancement above this temperature. For the hydrogenolysis reaction of FA to MF, a three times higher conversion was observed with $\mathrm{MF}$ as the major identified product. The carbon balance analysis after $5 \mathrm{~h}$ of the HDO reaction of FFR results in nearly $100 \%$ if considering the existence of gas-phase products, mainly hydrocarbons. For the conversion of FA, no gas-phase products were observed suggesting there is 


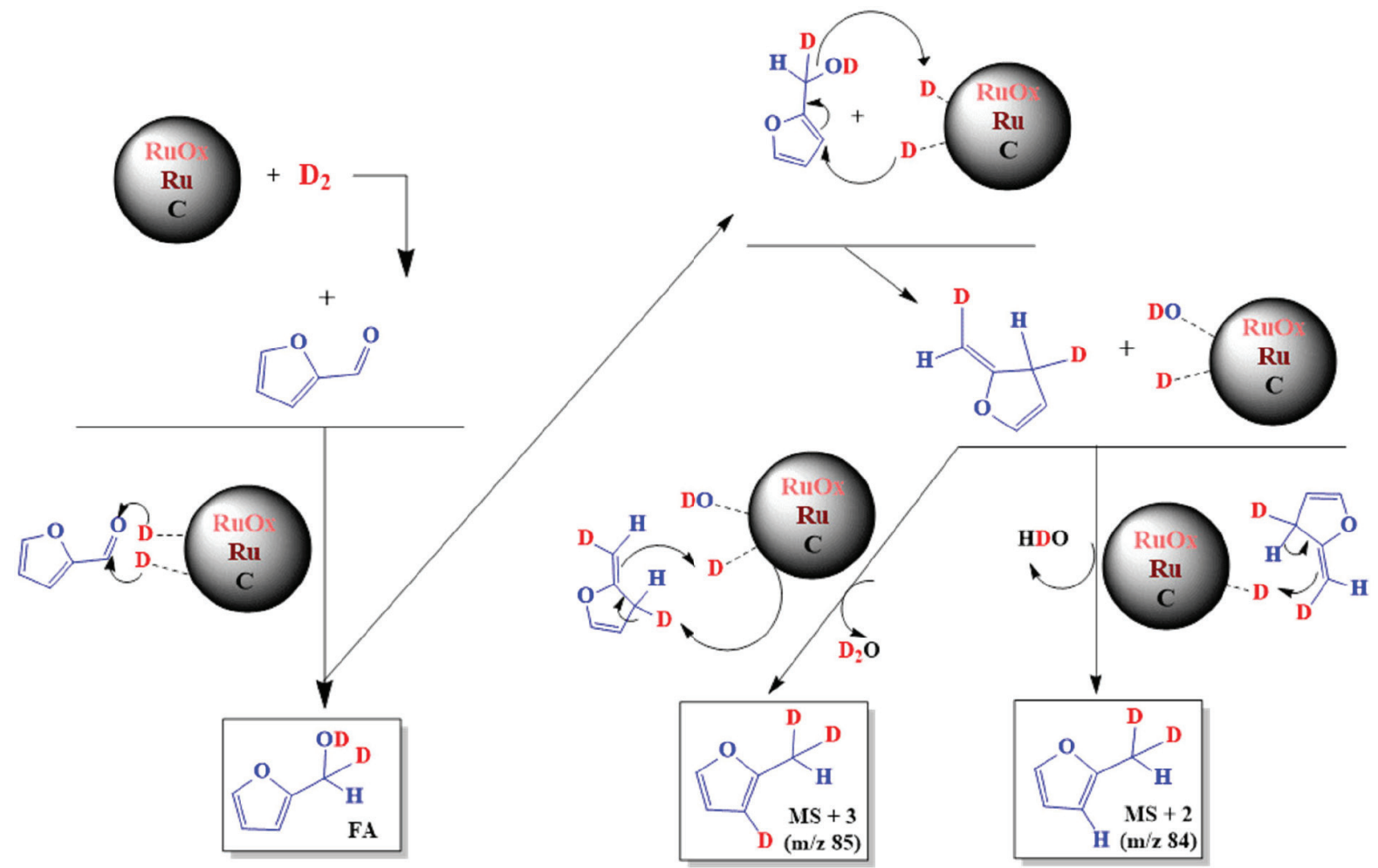

Scheme 3. Suggested mechanism for the conversion of FFR to MF including the hydrogenation and hydrogenolysis pathways.

no cracking of the $\mathrm{C}-\mathrm{C}$ bonds and that $\mathrm{FA}$ is much more reactive toward the formation of liquid-phase products in respect to FFR. The mass spectra monitoring of the kinetic isotope effect indicated the HDO reaction of FFR to MF occurs through a two-step mechanism comprising of an initial ruthenium-mediated hydrogenation reaction of FFR to FA. In the second step, the FA thus formed experiences a hydrogenolysis reaction via ring activation where the hydrogen atoms are firstly attached to the $\mathrm{C} 3$ carbon generating a ring activated structure and removing the $\mathrm{OH}$ group. The observation in the mass spectra of the MF product of the peaks at $m / z, 85$ and 84 assigned, respectively, to MF- $d_{3}$ and MF- $d_{2}$ species, confirmed this reaction pathway.

\section{Supplementary Information}

Supplementary data are available free of charge at http://jbcs.sbq.org.br as PDF file.

\section{Acknowledgments}

Longhinotti, E. (No. 306896/2018-4) and Diógenes, I. C. N. (No 307078/2017-5) are thankful to CNPq for the grants and FUNCAP/ PRONEX/2015 PR2-010100030.01.00/15 SPU No. 3265612/2015 for financial support. Sousa, A. F. thanks CAPES through the PDSE
(No. 99999.003191/2014-01). The authors are grateful to Dr Matthew Gilkey, Prof Bingjun Xu and Prof Dionisios G. Vlachos at University of Delaware (Catalysis Center for Energy Innovation, an Energy Frontier Research Center funded by the U.S. Department of Energy, Office of Science, Office of Basic Energy Sciences) for experimental support and valuable contributions and suggestions.

\section{References}

1. Shabih, F.; Amir, H.; Muhammad, N.; Temoor, A.; Muhammad, S.; Mohsin, T.; Imran, S.; Romana, T.; Protein Pept. Lett. 2018, $25,148$.

2. Pallapolu, V. R.; Lee, Y.Y.; Garlock, R. J.; Balan, V.; Dale, B. E.; Kim, Y.; Mosier, N. S.; Ladisch, M. R.; Falls, M.; Holtzapple, M. T.; Sierra-Ramirez, R.; Shi, J.; Ebrik, M. A.; Redmond, T.; Yang, B.; Wyman, C. E.; Donohoe, B. S.; Vinzant, T. B.; Elander, R. T.; Hames, B.; Thomas, S.; Warner, R. E.; Bioresour. Technol. 2011, 102, 11115.

3. Hu, J.; Arantes, V.; Saddler, J.; Biotechnol. Biofuels 2011, 4, 36.

4. Taha, M.; Foda, M.; Shahsavari, E.; Aburto-Medina, A.; Adetutu, E.; Ball, A.; Curr. Opin. Biotechnol. 2016, 38, 190.

5. Guffey, F. D.; Wingerson, R. C.; Fractionation of Lignocellulosic Biomass for Fuel-Grade Ethanol Production; U.S. Department of Energy Office of Scientific and Technical Information; USA, 2002, DOI: 10.2172/807155. 
6. Sarkar, N.; Ghosh, S. K.; Bannerjee, S.; Aikat, K.; Renewable Energy 2012, 37, 19.

7. Szczodrak, J.; Fiedurek, J.; Biomass Bioenergy 1996, 10, 367.

8. Venkateswar, L. R.; Goli, J. K.; Gentela, J.; Koti, S.; Bioresour. Technol. 2016, 213, 299.

9. Swain, M. R.; Krishnan, C.; Ind. Crops Prod. 2015, 77, 1039.

10. Kim, T. H.; Kim, J. S.; Sunwoo, C.; Lee, Y. Y.; Bioresour. Technol. 2003, 90, 39.

11. Lange, J.-P.; van der Heide, E.; van Buijtenen, J.; Price, R.; ChemSusChem 2012, 5, 150.

12. Sutton, A. D.; Waldie, F. D.; Wu, R.; Schlaf, M.; Silks III, L. A. P.; Gordon, J. C.; Nat. Chem. 2013, 5, 428.

13. Lee, W.-S.; Wang, Z.; Zheng, W.; Vlachos, D. G.; Bhan, A.; Catal.: Sci. Technol. 2014, 4, 2340.

14. Gilkey, M. J.; Panagiotopoulou, P.; Mironenko, A. V.; Jenness, G. R.; Vlachos, D. G.; Xu, B.; ACS Catal. 2015, 5, 3988.

15. Zhang, J.; Dong, K.; Luo, W.; Guan, H.; ACS Omega 2018, 3, 6206.

16. Panagiotopoulou, P.; Martin, N.; Vlachos, D. G.; J. Mol. Catal. A: Chem. 2014, 392, 223.

17. Nakagawa, Y.; Tamura, M.; Tomishige, K.; ACS Catal. 2013, $3,2655$.

18. Besson, M.; Gallezot, P.; Pinel, C.; Chem. Rev. 2014, 114, 1827.

19. Wang, C.; Xu, H.; Daniel, R.; Ghafourian, A.; Herreros, J. M.; Shuai, S.; Ma, X.; Fuel 2013, 103, 200.

20. Iqbal, S.; Liu, X.; Aldosari, O. F.; Miedziak, P. J.; Edwards, J. K.; Brett, G. L.; Akram, A.; King, G. M.; Davies, T. E.; Morgan, D. J.; Knight, D. K.; Hutching, G. J.; Catal.: Sci. Technol. 2014, 4, 2280.

21. Panagiotopoulou, P.; Vlachos, D. G.; Appl. Catal., A 2014, 480, 17.
22. Barbaro, P.; Liguori, F.; Linares, N.; Marrodan, C. M.; Eur. J. Inorg. Chem. 2012, 2012, 3807.

23. Climent, M. J.; Corma, A.; Iborra, S.; Chem. Rev. 2011, 111, 1072.

24. Van de Vyver, S.; Geboers, J.; Jacobs, P. A.; Sels, B. F.; ChemCatChem 2011, 3, 82.

25. http://apps.webofknowledge.com, searched on February 20, 2019.

26. Jae, J.; Zheng, W.; Karim, A. M.; Guo, W.; Lobo, R. F.; Vlachos, D. G.; ChemCatChem 2014, 6, 848.

27. Wang, S.; Vorotnikov, V.; Vlachos, D. G.; ACS Catal. 2015, 5, 104.

28. Yang, P.; Xia, Q.; Liu, X.; Wang, Y.; Fuel 2017, 187, 159.

29. Chen, H.; Ruan, H.; Lu, X.; Fu, J.; Langrish, T.; Lu, X.; Mol. Catal. 2018, 445, 94.

30. Mäkelä, E.; Lahti, R.; Jaatinen, S.; Romar, H.; Hu, T.; Puurunen, R. L.; Lassi, U.; Karinen, R.; ChemCatChem 2018, 10, 3269.

31. Kim, T.; Assary, R. S.; Pauls, R. E.; Marshall, C. L.; Curtiss, L. A.; Stair, P. C.; Catal. Commun. 2014, 46, 66.

32. Choura, M.; Belgacem, N. M.; Gandini, A.; Macromolecules 1996, 29, 3839.

33. Jae, J.; Zheng, W.; Lobo, R. F.; Vlachos, D. G.; ChemSusChem 2013, 6, 1158.

34. Jaatinen, S. K.; Karinen, R. S.; Lehtonen, J. S.; ChemistrySelect 2016, $1,5363$.

35. Sitthisa, S.; Sooknoi, T.; Ma, Y.; Balbuena, P. B.; Resasco, D. E.; J. Catal. 2011, 277, 1.

Submitted: November 1, 2019 Published online: February 6, 2020 